\title{
The study between ancient classical literature reading and perfect one's personality
}

\author{
Huizhen SHEN \\ Pingdingshan Institute of Education \\ Pingdingshan, Henan 467000, China
}

\begin{abstract}
Great changes have been taken in the field of reading at present.Fashion reading and leisure reading has taken possesion of the majority of reading,which has occupied the ancient classical literature reading with its special fascination. The classical reading teaching of ancient writing is said to be the most important content in Chinese teaching.Therefore the Chinese teaching must be brave and face the reality,it is important for us to strengthen the education of cultural connotation and the meaning of humanity in order to improve and cultivate a sound personality and Chinese literacy. Reading the classical literature to improve the spirit of reading is not only the needs of Times,but also the choice of the history.Consequently,it is vital for us to study the effect of ancient classical literature reading and perfect personality.
\end{abstract}

Keywords- ancient literature, classical reading, personality

\section{INTRODUCTION}

With the development of economy and technology,people's sense of time and the pace of life are all increasing,utilitarianism and hedonism are become very popular for the moment.The content and the method of reading are all tend to be more efficient.Changes have been taken especially in the method of reading.The net literature is beloved by many people for its convenient and efficient.But with the method of reading and the content which is very rich,people condense their classical reading when expand the scope of reading.For example,more and more people prefer to read fashion magazine rather than read classical writing,especially the ancient classical literature.

\section{THE BACKGROUND AND THE MEANING OF THE ANCIENT CLASSICAL LITERATURE RESEARCH.}

In the contemporary society,it is a time when utilitarianism and fast culture to be in vogue.This is a topic which we cannot say it clearly,but we should advocate the classical literature reading,for which the significance of value is everlasting.

The domestic research:In the 20th century,traditional classical,included the ancient classical literature were tended to change from hard to easy,transformed from ancient Chinese prose to vernacular language, which has reflected the development of ancient classical literature reading in a popular style.With the development of technology and the change of social culture,more ang more people prefer to read leisure books rather than read classical readings.Thus in
1995,Caoyu,Xiayan and other people put forward to construct the young traditional school in the Chinese People's Political Consultative Conference which has caused the attention of the society.The introduction of Chinese culture for children had been pushed to the whole society until 1998. Shengtao School had been established with the traditional character in the same year.Other projects had been also started in the same year.People who had won the Nobel Prize in 1998 had said that if people wanted to keep up living in the new century,they should get back to 2500 years ago,and search Confucius to look for what they want.How to understand the meaning of Chinese culture and how to absorb the wisdom of the people is related to the culture life at present,we should respect the diveristy of culture.Therefore we can conclude that the experts and scholors should based on the contemporary study,they should combined the study on classical literature reading with quality-oriented education,they should advocate the schools to push forward to this project,in order to reach the purpose of inherit the national spirit and the culture.

Foreign research:In 1982,the United Nations Educational Scientific and Cultural Organization put forward a goal to construct the reading society.In 1995 the organisation had announced that in order to remember the death of Cervantes and Shakespeare,April $23^{\text {rd }}$ was settled to be the World Reading Day.In the meanwhile, it also made the first task of the public library that the library should strengthen the reading habit of the young children.

Japan had pushed a law of children's reading in2001, and also made the World Reading Day to be the Children's Reading Day.At the same time,the country is a cartoon developed country and they had their own reading weeks.They had developed many Parents-children reading activities since 1960,so that the parents could accompained their children at least 20 minutes for reading one day

England put great emphasis on their national masterpiece and they also introduced England literary works to their students by asking students in grade7-11 learn about the theatre of Shakespeare and other famous poets.England's Reading Year is between September1998 to August1999.The education minster Blanch swear to build a country filled with the smell of books.

France had the custom of national reading .The France Reading Festival which had hold by the government and The Ministry of Foreign Affairs was one of the most important activities.China had been joined the club for 7 years since 1999.The communication between Chinese and France Reading Festival could boost the development of reading Chinese classical literature and France classical literature. 
America has always advocates classical reading,especially traditional classical reading,they want to make change through the spirit of literacy works.In the early 20th,Columbia university established two required course which had called'literature character' and'contemporary culture'.They also provided Europe literature masterpiece,philosophy and social theory for students to select.Furthermore,it had also developed many activities such as American's reading challenge,NewYork is the country of book and so on.

It is of great significance for reading no matter it is in teaching or classical reading.

\section{THE SIGNIFICANCE OF CLASSICAL READING}

The ancient classical reading really results in our consideration over some social phenomena and it is the record for our sublime thought.It is wisdom and enlighting.Thus we can enrich our experience by the communication between classical literature reading and the soul.We can make full use of language to enrich our content system step by step.Classical literature reading is also in favour of reading ability, it is a king of deep reading that can perfect one's personality.
Therefore,classical reading plays an irreplaceable role and has far-reaching meaning on the society.Classical reading also plays an important role in Chinese teaching even though people have different kinds of experience and value orientation.Our times calls for the regular pattern and the characteristic of classical reading.

\section{THE TEACHING METHOD OF THE ANCIENT CLASSICAL READING.}

Traditional classical reading had also accounted for the main part of the teaching. The educational community is lack of supervision on classical reading,we should solve the problem in time.

\section{A. The training of healthy psychology of reading}

The psychology of reading is useful in the process of reading.It can reflect the action and influence the effect.According to a recent survey,students did not have a postive reading psychology.In fact,good reading habits can produce postive actions.At the same time,the effect of reading have influence on the action of reading and then lead favourable response. As is shown in the graph:

\section{Table 1. The effect of reading have influence on the action of reading}



According to a recent survey,we can find that the reading psychology of the students is far from satisfactory.As is shown in the graph

Table 2 . The reading psychology of the students

\begin{tabular}{|l|c|c|}
\hline Sampling study & $\begin{array}{c}\text { Have no intersted in } \\
\text { reading }(\boldsymbol{\%})\end{array}$ & Intersted in reading (\%) \\
\hline SchoolA & 33.6 & 19.2 \\
\hline SchoolB & 55.4 & 18.9 \\
\hline SchoolC & 65.4 & 17.8 \\
\hline SchoolD & 57.8 & 14.9 \\
\hline SchoolE & 66.4 & 22.3 \\
\hline SchoolF & 68.9 & 20.3 \\
\hline
\end{tabular}

As can be seen from the chart above,the majority of schools have no intersted in reading.Therefore,classical reading must be sure to put an end to bad reading psychology, the school should help to correct the bad habits of their students.In order to reach this goal,effective measures should be taken:
First of all,they should correct the blind obedience mentality.Teenagers always wants to follow the others and they wants to try everthing at present.For example, if you find someone are reading fantasy novel,you will find other people read the same.They did not have the ability to think independently,so the students should read carefully with a 
specific purpose,they can learn a lot of things from the classical reading and finally they will enjoy it very much.

Furthermore,they should change their emotionize mentality, in this modern society, many people become more and more emotional and it will have a negative influence on children.People will rest on their laurels when they failed to reach their goals. So we should encourage them to have a common heart and to be a person of great perseverance no matter how difficulty it is.

B. reconstruct the right purpose of reading

Because of the influence of examination-oriented education,students could not get out of the shadow of modern reading when they are doing literary reading.The teaching of ancient classical reading is more than simply present the history and literature.

We should use the way of linguistic when we compile the textbook.The ancient classical reading often use exam as a guideline,we analysis the words and scentence but the idea is often one-side.Therefore,the ancient classical literature reading should base on the ancient literary classics and we need to build a circumstance for students to research in order to improve the ability.

Different from other ways of reading,classical reading is the crystals of human's wisdom.It is not easy to understand the real meaning of literature of oriental color.For example,when we study about "Laozi'"'Spring and Autumn","National language","ZhanGuoCe", they help us a lot to cultivate our brains.We can get some philosophic thinking from"Laozi", and we could also notice the importance of words from the book"National language"

When we read about the poem"Life is but adream,let me pour a libation to the river with moonlight gleam"wrriten by Sushi in"NianNuJiaoChiBi",we were deeply impressed that Sushi is man who had a negative attitude towards life..Different from Libai and Taoyuanming,Sushi suffered a lot of misfortune,but he did not lose his heart.On the contrary, he became a person who is big-hearted and had a postive heart to get into the society.He had also wrote some other poems to express feelings such as"ShuiDiaoGeTou".For instance, When we read about the poem

"ChouLeTianYangZhouChuFengXiShangJianZeng"written be LiuYUXi,we should know the innovation of Yongzhen,we must realize his degrade to Langzhou and Luoyang which made him away from home for 23 years.How to understand the topic of poem"A thousand sails pass by the shipwrek, Ten thousand saplings shoot up beyond the withered tree-new things come to the fore while old things die"?Baijuyi and Liuyuxi always exchange their their poems to encourage each other.In Tai Wo Estate7,their friends died in succession.Baijuyi made a pome of four lines to Liuyuxi and Liuyuxi made"LeTian"in return.When we know about the background of the poem,we can easily understand the topic of the poem.

\section{Find the appropriate reading method.}

The ancient classical reading is a world of imagnation and it always make reader indulge in the reading world. So we need to find all kinds of reading methods.The teaching of classical reading constantly put forward new requests and the teaching should find the energy from the ancient literature classics and also need to take care all of the students carefully.

The teaching of the ancient classical reading was the first step faced to the works.It is important to read more and more reading notes. They need to heip the students to find entrance to reading books by contact with many literature classics and information. They also have to find an opening to the solution of the problem in different point of view and then lead to deep reading.

In the meanwhile,the ancient classical reading is a process of gradual accumulation and a process of enrich ourselves.It is better to take oue time to entrance the way of reading than to hurry and make mistakes.Proceed in an orderly way and step by step means we should work hard at ordinary times.The teacher could only solve the most important problems in the class,many students could not read the literature books because of the homework. So the students should make a good arrangement of their time.

Take the senior high school student as an example,we ask them to read a classical every four weeks. The first week is the study of classics, it demand the students to spend half hour to read a classical book everday.They pick out 20 masterpiece from"The full-time ordinary senior middle school Chinese Teaching Syllabus" for study.The students could study some classics during their spare time.They could also watch the movie which is recompose by the classics in order to arouse the students's interested in the ancient classical reading. And the teachers could introduce the background of the writer's creation and ask the students to evaluate.

Paying attention to the content and the characteristic of the students's psychology,we need to put the teaching in the right order.For example, if we want to really kow about $\mathrm{DuFu}$,we need to read his poem at first.The teacher could put some pomes together for better understanding such as"DengGao","WangYue'and so on.It can not only brode the student's horizon but also cultivate the reading methods.

The teaching of the ancient classical reading is full of humanistic value and human relationship.Different from other teaching,the teaching of classical literature reading has its own appreciation of beauty.The teacher must realize the real purpose of the teaching and establishi the right purpose of teaching and find the best way to read teaching.The teachers should walk away from the misunderstanding ideas to find the true meaning of reading.

\section{CONCLUSIONS}

In this society,reading is still the best way to know about the knowledge and it is also the foundmental of innovation.It can stimulate people's imagination and perfect one's glamour of personality. Only by paying much more attention to the classical reading can we hope to witness the ideal scences in which we enjoy our life to the utmost. 


\section{References}

[1] Ma Xiao-xia.study of Chinese teaching:Zhejiang Univeristy Press, 2001

[2] Wang Song-quan.reading education:Liaoning Univeristy Press, 1995

[3] Wang Rong-sheng.basic course of Chinese.Shanghai Education Press, 2003

[4] Jiang Cheng-li.unscramble the Chinese course. Zhejiang Univeristy Press, 2000

[5] Qian Li-qun.reading the masterpiece.Shanghai Education Press, 1996

[6] Wang Shang-wen.sense of language. Shanghai Education Press, 2000

[7] Ge Zhao-guang.ten classics of China.Shanghai Bookstore Press, 2002

[8] Adelle.M.J.how to read a book.Shanghai Translation Press, 1991

[9] Reedpaz.Peter.revolution of reading.China Science\&Technology Press, 2001
[10] Chen Han-sheng.ancient language of China.Social Science Documentation Press, 1996

[11] Gao Xin-yong.literature reading.Peking Univeristy Press, 1998

[12] Michael.personal konwledge.GuiZhou People's Publishing Press, 2000

[13] Yuan Pei-yao.method of classical reading.Journal of Yueyang Technical College, 2014,(4):46-48

[14] Gan Wen-quan.teaching of classical reading,2012,(6):285-285 